\title{
Effect of environmental salinity on sea lice Lepeophtheirus salmonis settlement success
}

\author{
Ian R. Bricknell ${ }^{1, *}$, Sarah J. Dalesman ${ }^{1,2}$, Bríd O'Shea ${ }^{1,2}$, Campbell C. Pert ${ }^{1}$, \\ A. Jennifer Mordue Luntz ${ }^{2}$
}

\begin{abstract}
${ }^{1}$ Aquaculture \& Aquatic Animal Health, FRS Marine Laboratory, 375 Victoria Road, Torry, Aberdeen AB11 9DB, UK
${ }^{2}$ Department of Zoology, School of Biological Sciences, University of Aberdeen, Tillydrone Avenue, Aberdeen AB24 2TZ, UK
\end{abstract}

\begin{abstract}
The sea louse Lepeophtheirus salmonis (Krøyer, 1837) (Copepoda: Caligidae) is an ectoparasite of salmonid fish. It has earlier been proposed that the free-swimming infectious copepodid stage of L. salmonis gather at river mouths to infect wild Atlantic salmon Salmo salar L. and sea trout $S$. trutta L. smolts during their seaward migration. This study used aquarium-based methods to investigate the survival, infective ability and behaviour of $L$. salmonis copepodids exposed to short periods of low salinity levels, such as those encountered at river mouths. Survival of free-swimming copepodids was found to be severely compromised at salinity levels below 29 parts per thousand (ppt). Attachment to an $S$. salar host did not aid copepodid survival during post-infection exposure to low salinity environment, and a reduction in salinity appears to reduce the ability of copepodids to remain attached to $S$. salar smolts. Pre-infection exposure of copepodids to reduced salinity levels reduced infection of $S$. salar. Infection levels at reduced salinity were lower than predicted from the free-swimming survival experiment, suggesting that low salinity compromises the copepodids' ability to sense or respond to the presence of a host. In salinity gradients, copepodids demonstrated avoidance of salinities below 27 ppt, by both altering their swimming behaviour and changing the orientation of passive sinking. Avoidance of low salinity levels may be due to their adverse effects on copepodid physiology, as suggested by the reduction in survival. Sinking rates were also faster in reduced salinity, suggesting that remaining in the water column would be more energetically demanding for the copepodids at reduced salinity. These results show that both survival and host infectivity of $L$. salmonis are severely compromised by short-term exposure to reduced salinity levels.
\end{abstract}

KEY WORDS: Sea lice $\cdot$ Infection rate $\cdot$ Hyposalinity $\cdot$ Survival $\cdot$ Salinity gradients

Resale or republication not permitted without written consent of the publisher

\section{INTRODUCTION}

The sea louse Lepeophtheirus salmonis is an ectoparasitic copepod of salmonid fish, with a circumpolar distribution in the Northern Hemisphere, where historically it occurs at low levels of infestation on wild salmonids (Pike \& Wadsworth 2000, Tully \& Nolan 2002). In Western Europe, host species include Atlantic salmon Salmo salar L., Arctic charr Salvelinus alpinus L. and sea trout Salmo trutta L. (Pike \& Wadsworth 2000). The life cycle of $L$. salmonis comprises 5 distinct phases and 10 stages (Schram 1993). There are 2 naupilii stages (Naupilii I and II) followed by the infective copepodid stage, which actively seeks a host. This is followed by the immobile chalimus stages (Chalimus I to IV), which are attached to the host by means of a frontal filament. The final stages are the mobile preadult stages (Pre-adult I and II) and the reproductive adult stage.

Since the mid-1970s, the growth of the salmonid aquaculture industry has led to Lepeophtheirus salmonis becoming the focus of attention due to the high levels of infection occurring on salmon farms (Costello 1993). Costs associated with loss of fish and treatments for L. salmonis are estimated at between £20 and $£ 30$ million pounds sterling each year for the Scottish salmon industry alone (Pike \& Wadsworth 2000). 
In Scotland, a dramatic decline in wild sea trout populations has occurred. Several factors including pollution and overfishing may have contributed to this decline (Parrish et al. 1998, Scott 2001), but salmon farms are also cited as a possible factor through transmission of parasites from farmed to wild fish (Berland 1993). Farmed salmon often carry a significant Lepeophtheirus salmonis burden, both in prevalence and abundance. In extreme cases, farmed salmon carry a higher louse burden than wild salmon. Whilst this maybe an artefact of high stocking density and overlapping of fish cohorts present on farms (Costello 1993, Costello et al. 1996), Butler (2002) hypothesised that high infection loads on salmon farms are directly related to high infection levels in wild salmonids.

Sampling studies in the open estuarine environment by Costello et al. (1996) and Tully et al. (1999) showed that copepodids have an overall low seasonal abundance, with periods of higher intensity associated with salmon farms and river mouths. No relationship between larval abundance and the number of ovigerous lice on the farm was found (Costello et al. 1998a). There is also an indication that the nets surrounding salmon farms restrict water movement, and the majority of hatched larvae are retained within the farm (Costello et al. 1996). Bjørn et al. (2001) reported higher rates of infection in sea trout and Arctic charr in an area of close proximity to salmon farms compared to a region with no farms. However, as only 2 sites were sampled, other factors may have been involved. Infection of wild salmonids was higher in bays containing lice-infested salmon farms in Ireland (Tully et al. 1999), whereas there was no evidence of this pattern in Scottish waters (MacKenzie et al. 1998).

In regions where salmon farms are not present, infection of sea trout with Lepeophtheirus salmonis tends to have a very patchy distribution, with variation both within and between bays (Tully et al. 1999). The evidence that points towards increases in L. salmonis infection in wild salmonids as a result of salmon farms is largely circumstantial, with no evidence of a causal link between infection on farms and wild fish. There is some evidence that Atlantic salmon smolts become infected with L. salmonis shortly after leaving freshwater (Finstad et al. 2000). However, prevalence of $L$. salmonis on grilse and adult Atlantic salmon tend to be lower than on fish that have spent 2 winters feeding at sea, implying an accumulation of parasites during the oceanic phase of the Atlantic salmon's life cycle (Jacobsen \& Gaard 1997). To date there are no direct studies that can confirm whether or not infection takes place at river mouths (Finstad et al. 2000) and, as such, it is unknown if copepodids gathered around river mouths are still infective (Costello et al. 2004, McKibben \& Hay 2004).
Copepodids have been found in high concentrations around river mouths, particularly in spring during the seaward migration of salmon smolts (Costello et al. 1998a,b, 2004, Carr \& Whoriskey 2004, McKibben \& Hay 2004). Lepeophtheirus salmonis copepodids are stenohaline, suggesting their activity and survival would be severely compromised in waters of reduced salinity (Pike \& Wadsworth 2000). Sporadic abundance around river mouths was negatively correlated with rainfall, suggesting that a decrease in salinity through increased rainfall reduces copepodid abundance (Costello et al. 1998b).

Heuch (1995) reported that Lepeophtheirus salmonis copepodids maintained in a linear salinity gradient aggregated in salinities of 19 to 24 parts per thousand (ppt) during light conditions, and in salinities as low as 15 to 17.2 ppt in darkness, despite having the option of high saline conditions. Theoretically the lice would be compromised at these salinity levels if they were stenohaline, resulting in negative buoyancy and an energetic output in order to remain in position. When stepsalinity gradients were used, with a decrease of $15 \mathrm{ppt}$ in the upper layer, copepodids aggregated just below the halocline irrespective of light condition. In homogenous $30 \mathrm{ppt}$ salinity they aggregated at the surface during light conditions (Heuch et al. 1995). This suggests that copepodids are highly competent at sensing salinity levels, are able to tolerate low salinity conditions, and may be actively orientating towards haloclines. This behaviour may allow them to come into contact with odour trails in the water (that tend to be carried further above haloclines) and orientate towards river mouths, where they are more likely to come into contact with migrating smolts (Heuch 1995, Heuch et al. 1995).

Reduced salinity levels have been found to reduce settlement of copepodids on Salmo salar (Tucker et al. 2000a). It is possible that reduced salinity interferes with host identification or activity of the copepodids, or impacts copepodid survival. The response of copepodids to varying salinity gradients implies that they choose salinity levels lower than their optimal level for survival and infection (Heuch 1995).

The aim of this study was to investigate the impact of decreased salinity on the survival, infectivity success and behaviour of the sea louse Lepeophtheirus salmonis.

\section{MATERIALS AND METHODS}

Louse collection and cultivation. Mature female sea lice Lepeophtheirus salmonis with egg strings were collected from Atlantic salmon Salmo salar during harvests at a commercial fish farm on the west coast of Scotland. The lice were transported to the Fisheries 
Research Services (FRS) Marine Experimental Unit, Aultbea, in bags of seawater in insulated cool boxes with ice packs. Egg strings were dissected from the females and placed in one of two $15 \mathrm{l}$ aquaria containing fresh seawater at $12 \pm 1.5^{\circ} \mathrm{C}$. Aquaria were maintained under ambient long-day lighting regimes (May to June). The water was aerated to ensure the egg strings were constantly suspended and moving in the chamber. The hatching and development of larval $L$. salmonis was monitored on a daily basis by taking $50 \mathrm{ml}$ subsamples from each of the chambers. Larvae were only used for experiments when a minimum of $70 \%$ of the nauplii had moulted to the infectious copepodid stage. All experiments were carried out within $72 \mathrm{~h}$ of the larvae reaching the copepodid stage.

Survival of Lepeophtheirus salmonis copepodids at different salinities. Ten 11 beakers (VWR, UK) were set up in triplicate with $800 \mathrm{ml}$ of water at varying salinity levels from $10 \%$ seawater (5 ppt) to $100 \%$, full salinity seawater (36 ppt), in steps of 3 to $4 \mathrm{ppt}$. Salinity measurements were recorded using a Pinpoint ${ }^{\mathrm{TM}}$ salinity monitor (American Marine). The water in each beaker was aerated with a commercial air pump (Rena). Copepodids from the hatching chamber were passed through a $100 \mu \mathrm{m}$ sieve, rinsed with fresh seawater and transferred to a $1 \mathrm{l}$ beaker containing $100 \%$ seawater. The copepodids were then left to stand for 10 min below a $40 \mathrm{~W}$ daylight, balanced light source (Daylight Company). Only copepodids attracted to the light source and actively swimming were used in the experiment. Using a plastic wide bore pipette, approximately 100 copepodids were transferred into the beakers containing the dilute seawater, and the time noted.

Aeration was ceased $50 \mathrm{~min}$ after introducing the copepodids to the beaker, and the beaker was placed under the light source. After $10 \mathrm{~min}$, any copepodids not actively swimming were removed into a Petri dish with a white background and stimulated with a jet of water from a pipette. Any copepodids not responding to the stimuli were deemed to have died, and these were counted and removed. Any copepodids that demonstrated activity were returned to the beaker and aeration recommenced. This process was repeated for each beaker every hour for $6 \mathrm{~h}$. The period of $6 \mathrm{~h}$ was chosen as the predicted period of exposure of copepodids to reduced salinity at a river mouth during half a single tidal cycle (i.e. running from minimum to maximum salinity). After $6 \mathrm{~h}$, all surviving copepodids in each beaker were filtered through a $100 \mu \mathrm{m}$ mesh and counted. The total number of copepodids in each beaker at the start of the experiment was verified by adding the number of surviving copepodids to the number of copepodids that had died, and the death rate at each salinity level was calculated.
Behavioural responses to salinity. Step gradients: All experiments were undertaken in $100 \mathrm{ml}$ measuring cylinders (Greiner) with the volume markers used to verify the boundaries between different salinities. Cylinders were lit from above with a $40 \mathrm{~W}$ daylight, balanced light source (Daylight Company). We made up 5 seawater dilutions solutions consisting of $0 \%$ seawater (0.6 ppt) to $100 \%$ seawater (36 ppt) in steps of $25 \%$ (8 to $9 \mathrm{ppt}$. We carefully layered $20 \mathrm{ml}$ of water at each salinity onto each other to form a discontinuous salinity gradient, with $100 \%$ seawater distributed between 0 and $20 \mathrm{ml}$ and $0 \%$ seawater between 80 and $100 \mathrm{ml}$, using a Masterflex 7554 peristaltic pump (Cole-Palmer) to deliver the diluted seawater at $3 \mathrm{ml} \mathrm{min}{ }^{-1}$. The other stepwise dilutions lay between these extremes. Once the salinity gradient had been established, 30 actively swimming copepodids (see foregoing subsection) were added to the lowest band containing full strength seawater (0 to $20 \mathrm{ml})$.

We set up 2 types of salinity gradient column. The first (multiple-step column) contained five $20 \mathrm{ml}$ bands ranging from $100 \%$ seawater at the bottom of the column to $0 \%$ seawater at the top, in steps of $25 \%$. The distribution of copepodids was noted every 1 min for the first $10 \mathrm{~min}$, and thereafter every 30 and $60 \mathrm{~min}$. The second type of gradient column (single-step column) had full strength seawater (36 ppt) in the lowest 3 bands ( 0 to $60 \mathrm{ml}$ ) and $50 \%$ seawater (17.9 ppt) in the 2 upper bands (60 to $100 \mathrm{ml}$ ). Copepodid distribution within the column was noted as to the number of individuals within each of the 5 bands after $120 \mathrm{~min}$.

A control column containing full strength seawater in all bands was set up simultaneously and exposed to the same conditions as each test column. This was designed to allow direct comparison between the 'observed' distribution in the test columns and the 'expected' distribution in the full strength column. This experiment was carried out in 5 replicate groups of salinity columns and 5 control columns. The null hypothesis was that lower salinities would not affect the distribution of copepodids within the test columns.

Sinking rates: An experiment was designed to assess the sinking rate of inactive copepodids in columns of differing salinity $(6,9.9,17.9,27$ and $36 \mathrm{ppt})$ to establish the mean sinking rate at different salinities. Copepodids were anaesthetised with benzocaine (Sigma) at $2.5 \mu \mathrm{g} \mathrm{ml}^{-1}$ for $5 \mathrm{~min}$, and placed into the top of the salinity column. They were allowed to sink $5 \mathrm{~cm}$ down the column and then timed over a further $2.6 \mathrm{~cm}$. This was repeated with 25 copepodids at each of the 5 salinity levels with 5 replicate groups at each salinity.

Infection of Atlantic salmon Salmo salar. Atlantic salmon smolts from a wild population (River Don, Aberdeenshire, UK), provided by FRS Marine Research Station Aultbea, were used as potential hosts for 
Lepeophtheirus salmonis copepodids to assess infection and survival at different environmental salinity levels. The salmon had a mean fork length of $15.7 \pm$ $0.2 \mathrm{~cm}$ and mean weight of $31.8 \pm 1.1 \mathrm{~g}$. They were maintained on a $12: 12 \mathrm{~h}$ light:dark cycle at $12 \pm 3.5^{\circ} \mathrm{C}$.

Infection protocol. Active copepodids were collected from the hatching chambers by sieving through a $100 \mu \mathrm{m}$ mesh filter and rinsing with fresh seawater into a 11 beaker. Copepodid density was assessed by thoroughly mixing the sample and removing five $5 \mathrm{ml}$ aliquots into a Petri dish. The number of active lice was determined and the total number of copepodids in the beaker calculated. Fresh seawater was then used to dilute the lice to the desired density for infection.

Infection was carried out in all cases using a modification of Sevatdal's (2001) dip method. Copepodids were maintained at a concentration of $1.0 \pm 0.5 \mathrm{ml}^{-1}$ throughout infection. We anaesthetised 2 Atlantic salmon in MS222 (Sigma) at $0.08 \mathrm{~g} \mathrm{l}^{-1}$ and rinsed them briefly in fresh seawater to remove any residual anaesthetic. The salmon were then placed into the copepodid suspension for $30 \mathrm{~s}$. They were then allowed to recover from the anaesthetic in a $25 \mathrm{l}$ aquarium containing fresh seawater and, following recovery, transferred to the experimental tank.

Salinity levels. Salinity levels used during infection experiments were based on a range of salinities measured at the mouths of the rivers Balgey and Shieldaig, which drain into Loch Torridon on the west coast of Scotland (M. A. McKibben pers. comm.). The range varied from 4 to $34 \mathrm{ppt}$, and 5 salinities were chosen to cover this range: $4,12,19,26$ and 34 ppt. The salinity level was maintained to within $\pm 0.5 \mathrm{ppt}$ for each salinity during these experiments.

Pre-infection exposure to varying salinity regimes (Sampling Block 1). Copepodids were maintained in 11 aerated beakers at the 5 salinity levels for $3 \mathrm{~h}$ prior to infection. The density of active copepodids in each beaker prior to exposure was 0.75 copepodids $\mathrm{ml}^{-1}$. Infection of 12 Salmo salar smolts per treatment level was carried out using Sevatdal's dip method at a starting concentration of 1.5 lice $\mathrm{ml}^{-1}$. Infected $S$. salar were transferred to separate $100 \mathrm{l}$ aerated aquariums (at the appropriate salinity) and left for 30 min to allow any copepodid re-assortment to occur. The fish were then terminally anaesthetised using MS222 and were placed into individually labelled plastic bags. The water from each aquarium was filtered through a $100 \mu \mathrm{m}$ mesh to retain any copepodids that had dropped off.

Post-infection exposure to varying salinity (Sampling Block 2). Five 400 1, $1 \mathrm{~m}$ diameter tanks were set up with a mixed seawater/freshwater inflow, at $10 \mathrm{l}$ $\mathrm{min}^{-1}$. Each tank was randomly assigned to one of the treatments, and adjusted to the different treatment salinities $(4,12,19,26$ and $34 \mathrm{ppt} \pm 0.5 \mathrm{ppt})$. We placed
26 Salmo salar smolts in each tank and acclimated them for $24 \mathrm{~h}$. Following acclimation, each tank of fish was infected with Lepeophtheirus salmonis using the dip method described in an earlier subsection. Flow was maintained at the treatment salinity for a further $3 \mathrm{~h}$, after which the inflow was switched to full strength seawater $\left(10 \mathrm{l} \mathrm{min}^{-1}\right)$ to allow the water to gradually rise to full salinity. This reproduced the relatively rapid migration of $S$. salar and $S$. trutta smolts into the open ocean (Moore et al. 1998a,b) or the migration of sea trout to feed on the rising tide (McKibben \& Hay 2004). The salinity level in each tank was monitored for $5 \mathrm{~h}$ until all 5 tanks had reached full salinity. The resultant salinity profile showed an initial rapid rise in salinity followed by a more gradual increase (Fig. 1).

Following infection, the tanks were maintained at full salinity on a 12:12 h light:dark cycle. Fish were fed throughout the duration of the experiment. We destructively sampled 13 post-smolts from each tank at $2 \mathrm{~d}$ post-infection (dpi) to assess copepodid infection levels, and 13 fish from each tank at 6 dpi to assess chalimus infection levels.

Infection assessment. The number and position of copepodids and chalimus on the host's body were used to assess infection level. The position of individual Lepeophtheirus salmonis was noted and broadly assigned to 1 of 10 different regions: head, dorsal anterior, ventral anterior, dorsal posterior, ventral posterior, pectoral fin, pelvic fin, dorsal fin, anal fin or tail. Gill subsamples were taken from 4 smolts per treatment per sampling block to assess gill infection. This was carried out on a subsample only, as gill infection is thought to be an artefact of laboratory infection methods (Sevatdal 2001) and hence not of primary interest in this study. Any copepodids found in the labelled bags were added to the total found on each fish, but were not assigned to an attachment region. Chalimus

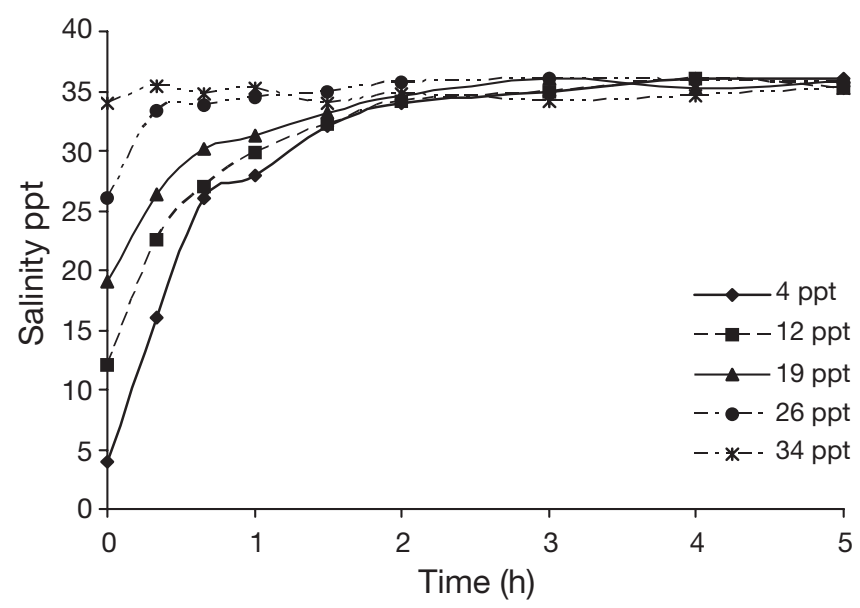

Fig. 1. Change in salinity profile over time after tank inflow had been switched to full strength (36 ppt) seawater 
stages, being physically attached by the frontal filament, did not drop off the fish post-sampling. The mass and length of each fish was also recorded to assess any relationship between fish size and infection level.

Data analysis. Survival under different salinity regimes was analysed by comparing the number of individuals alive and dead at 3 and $6 \mathrm{~h}$ using chi-squared analysis. Survival at each salinity was converted into the proportion alive at the end of each hour, and the duration over which $50 \%$ mortality $\left(\mathrm{LT}_{50}\right)$ occurred or was predicted to occur was calculated for each salinity level.

The distribution of copepodids within the salinity columns was analysed using 2-way analysis of variance (ANOVA). As raw data did not meet parametric assumption of homogeneity of variance and normal distribution, all data was square-root/arcsine transformed for analysis. The sinking rate of copepodids was analysed using a 1-way ANOVA with Tukey's pairwise comparisons (Minitab Version 12).

The mass and length of fish was compared between sampling blocks and treatments using 2-way ANOVAs. Infection levels of both copepodids and chalimus were analysed using generalised linear models (GLM, Genstat Version 6). Data from the lowest salinity level (4 ppt) was excluded from the analysis as no copepodids or chalimus stages were found on any of the fish at this treatment level. Data was assumed to follow a pseudo-Poisson distribution, and a log link function was used in model fitting. This allowed for overdispersion in the data (where the variance in most cases was greater than the mean) in fitting the model. Deviance values were approximately distributed as chi-square $\left(\chi^{2}\right)$ values, so comparison with $\chi^{2}$ tables was used to derive probability values. Because of the approximation of the statistic, the most conservative probability is presented.

The Mann-Whitney $U$-test was used for pairwise comparisons between the level of copepodid and chalimus infection. Positional data on copepodid and chalimus infection was compared by analysing the percentage infection in different regions using a 2-way ANOVA. The relationship between the lice infection on the outer surface of the fish and the number of copepodids on the gills was assessed using Spearman rank correlation.

\section{RESULTS}

\section{Copepodid survival}

Copepodid survival decreased significantly at lower salinity levels after $3 \mathrm{~h}$ exposure $\left(\chi^{2}=856.373, \mathrm{p} \leq\right.$ $0.001, \mathrm{df}=9)$ and $6 \mathrm{~h}$ exposure $\left(\chi^{2}=766.447, \mathrm{p} \leq 0.001\right.$, $\mathrm{df}=9$ ). The survival of free-swimming Lepeophtheirus salmonis copepodids did not differ significantly with salinity between 29 and 36 ppt. Below 29 ppt survival decreased with decreasing salinity, showing a relatively gradual reduction in proportion surviving at each time period down to $16 \mathrm{ppt}$. At $12 \mathrm{ppt}$ and below the initial death rate was rapid, with all copepodids in 9 and 5 ppt dying within the first $2 \mathrm{~h}$ (Table 1).

The $50 \%$ survival $\left(\mathrm{LT}_{50}\right)$ at $26 \mathrm{ppt}$ was half that at 29 ppt (Table 1). Survival decreased gradually from 11 $\mathrm{h}$ for $\mathrm{LT}_{50}$ at $26 \mathrm{ppt}$ to $4 \mathrm{~h} \mathrm{LT}_{50}$ at $16 \mathrm{ppt}$. At salinities less then $16 \mathrm{ppt}$, survival was severely decreased, with a mortality of $>50 \%$ within $1 \mathrm{~h}$ of exposure. However, a small proportion of individuals did seem able to remain alive at 12 ppt beyond the initial rapid mortality seen (Table 1).

\section{Step gradients}

There was a significant interaction between the salinity profile and the distribution of copepodids in the salinity column between multiple-step salinity gradients (Fig. 2B) and the control column (Fig. 2A; 2-way ANOVA: $F_{5,12}=5.06, p=0.01$ ). In the control column the highest percentage of copepodids was in the uppermost section of the column, with copepodids distributed throughout all sections of the column. In the multiplestep salinity gradient the highest percentage of copepodids was in the lowest section of the column in full strength salinity (36 ppt). No individuals were found in the 0.6 and 9.9 ppt bands. The distribution of copepodids in a column with a single step of $50 \%$ full strength seawater is shown in Fig. 2C. Copepodids in the 2 uppermost bands also varied significantly from the control column (2-way ANOVA: $\left.F_{5,12}=6.4, \mathrm{p}=0.004\right)$.

\section{Single salinity effects}

Throughout, the distribution of copepodids in a column containing $75 \%$ seawater ( $27 \mathrm{ppt}$ ) did not differ

Table 1. Lepeophtheirus salmonis. Estimates of duration of survival of $50 \%$ of free-swimming copepodids at various salinity levels

\begin{tabular}{|cc|}
\hline Salinity (ppt) & $50 \%$ survival duration $(\mathrm{h})$ \\
\hline 5 & $<1$ \\
9 & $<1$ \\
12 & $<1$ \\
16 & 4 \\
19 & 6 \\
23 & 8 \\
26 & 11 \\
29 & 24 \\
33 & 22 \\
36 & 25 \\
\hline
\end{tabular}



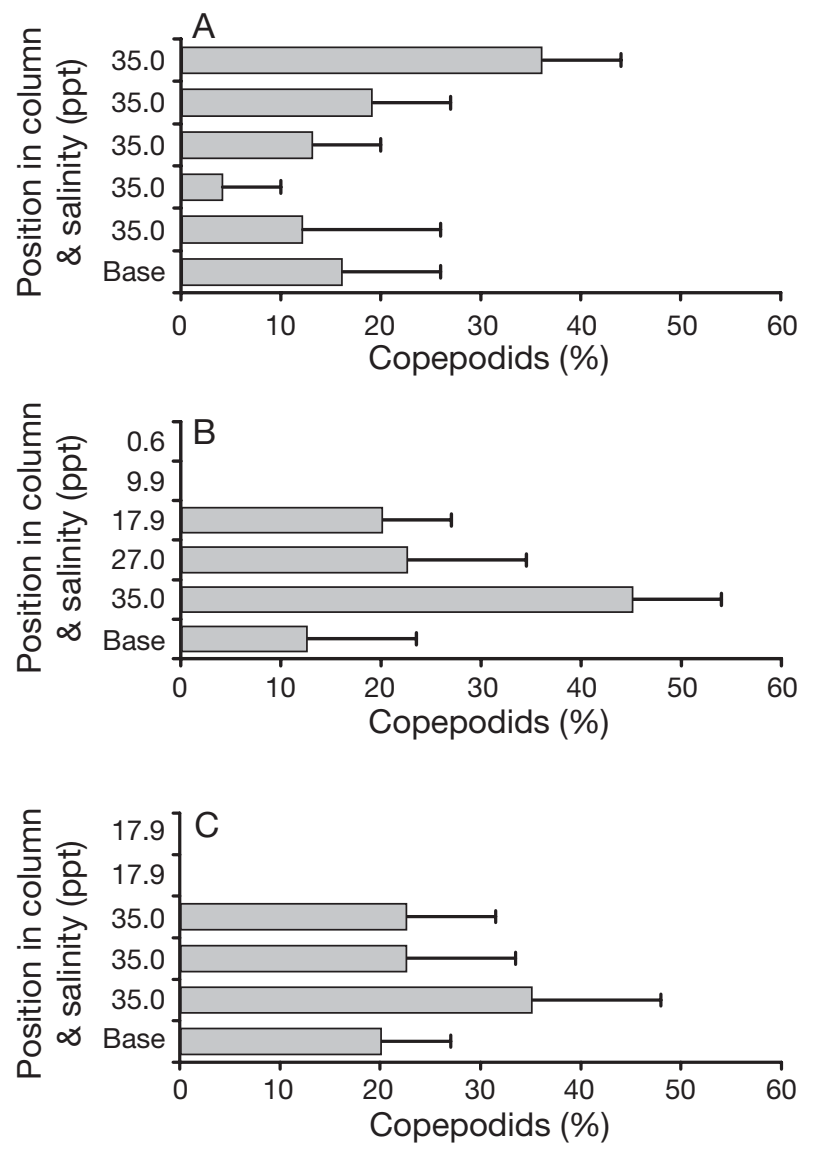

Fig. 2. Lepeophtheirus salmonis. Distribution of copepodids in (A) control column, (B) multiple-step salinity gradient, and $(C)$ single-step salinity gradient $(\mathrm{N}=60$ copepodids per column, 3 replicates)

significantly from that in the control column of $100 \%$ seawater (35 ppt). However, in a column containing only $50 \%$ seawater, significantly fewer copepodids were actively swimming (2-way ANOVA: $F_{1,12}=6.22$, $\mathrm{p}=0.028)$ and the active copepodids were distributed much lower in the column than in the control (2-way ANOVA: $F_{5,12}=19.30, \mathrm{p}<0.001, \mathrm{df}=5$ ), with $90 \%$ of active individuals only found in the lowest band. In columns containing 25 and $0 \%$ seawater statistical analysis was not possible, as there were no actively swimming individuals in any bands of the column.

\section{Behavioural observations}

During the salinity column experiments, the copepodids behaved differently in the different salinities. In a multiple-step salinity gradient they would swim upwards until they reached the lower salinities (50\% seawater, $17.9 \mathrm{ppt}$ ) where they would cease actively swimming and start to sink passively towards the bottom of the cylinder. In the bands containing $\leq 17.9 \mathrm{ppt}$ salinity they would sink in a vertical position or 'head first'. On reaching 75 or $100 \%$ seawater their orientation altered until they were positioned horizontally; this positioning appeared to slow their sinking rate. This behaviour was confirmed in the cylinders containing single seawater concentrations throughout the water column: in 100 and $75 \%$ seawater, sinking occured in the horizontal position, whereas in the 50, 25 and $0 \%$ seawater, passive sinking occurred in the vertical position. The only time that copepodids were observed actively swimming downwards was when they reached the 25 and $0 \%$ bands in the step salinity gradient. This was a rare observation and only occurred a few of times during the course of the experiment. In the control column, individuals in the upper bands of the column switched between swimming upwards and passive sinking behaviour to maintain their position near the top of the column, rather than continuous active swimming.

\section{Sinking rates}

The sinking rate of anaesthetised copepodids in the water column varied significantly with salinity level, with sinking rate increasing as salinity decreased (1-way ANOVA; $F_{4,95}=12.59, \mathrm{p}<0.001 ;$ Fig. 3 ). A minimum of $50 \%$ difference in salinity was required to produce significant variation in sinking rate (all data analysed by Tukey's pairwise comparisons). The sinking rate at 35 ppt was significantly slower than at 17.9 ppt or lower, but did not vary significantly from that at 27 ppt. Similarly, the sinking rate was significantly slower at $27 \mathrm{ppt}$ than at $9.9 \mathrm{ppt}$ or lower, but did not differ significantly from the rate at $17.9 \mathrm{ppt}$. There were no significant differences between the sinking rates at the lowest 3 salinity levels of $0.6,9.9$ and 17.9 ppt.

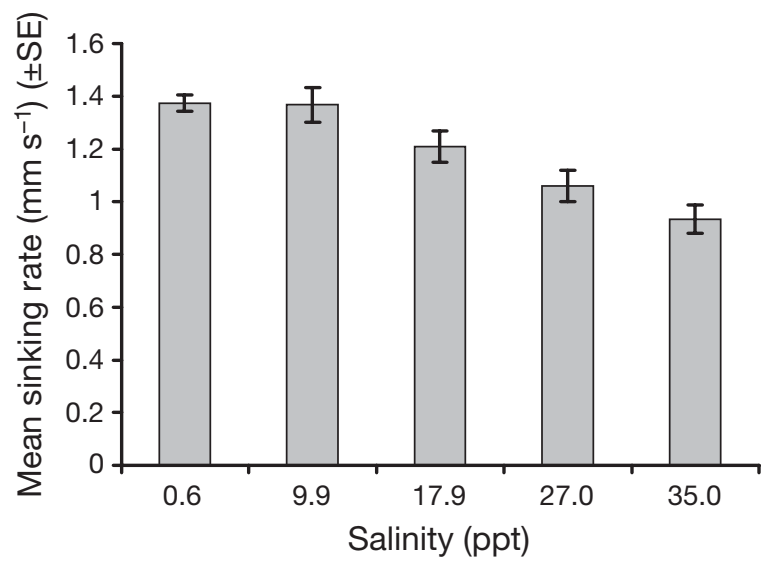

Fig. 3. Lepeophtheirus salmonis. Sinking rate of copepodids in different salinities ( $\mathrm{N}=25$ copepodids per salinity level) 


\section{Effect of salinity on infection}

Exposure of Lepeophtheirus salmonis copepodids to reduced salinity levels prior to infection of Salmo salar smolts significantly reduced the number of copepodids found attached to the smolts (GLM: $\chi^{2}=427.5, \mathrm{p} \leq$ 0.001, df = 3; Fig. 4). At 26 ppt the infection level was approximately $45 \%$ of that at $34 \mathrm{ppt}$. This is lower than would have been predicted from the survival experiment. The decrease in settled lice was less between 26 and 19 ppt (45 and $34 \%$ respectively of that observed in full strength seawater). There was a drop of $87.5 \%$ in the numbers of lice attached in 19 and $12 \mathrm{ppt}$; this was similar to the decrease in louse survival between these 2 salinities. At the lowest salinity, 4 ppt, there were no copepodids found on the fish. This concurs with the survival experiment, where no copepodids were found alive after $3 \mathrm{~h}$ at $5 \mathrm{ppt}$.

\section{Post-infection exposure to reduced salinity}

There was a significant decrease in the copepodid infection levels at each salinity level between the first and second sampling blocks of the experiment (GLM: $\chi^{2}=12.7, \mathrm{p} \leq 0.01, \mathrm{df}=1$ ). However, no significant interaction was found between the effect of salinity level on copepodid infection and effect of the sampling blocks. Therefore, data from both blocks was combined for analysis. There was no significant effect of block on the level of chalimus infection, either as a main effect or as an interaction.

Exposure of Lepeophtheirus salmonis to reduced salinity following infection of Salmo salar significantly reduced both the number of copepodids (GLM: $\chi^{2}=$ 260.8, $\mathrm{p} \leq 0.001, \mathrm{df}=3$ ) and the number of chalimus (GLM: $\chi^{2}=106.0, \mathrm{p} \leq 0.001, \mathrm{df}=3$ ) attached to the fish. No copepodids or chalimus were found attached to fish exposed to the lowest salinity level in Treatment 1 at $4 \pm$

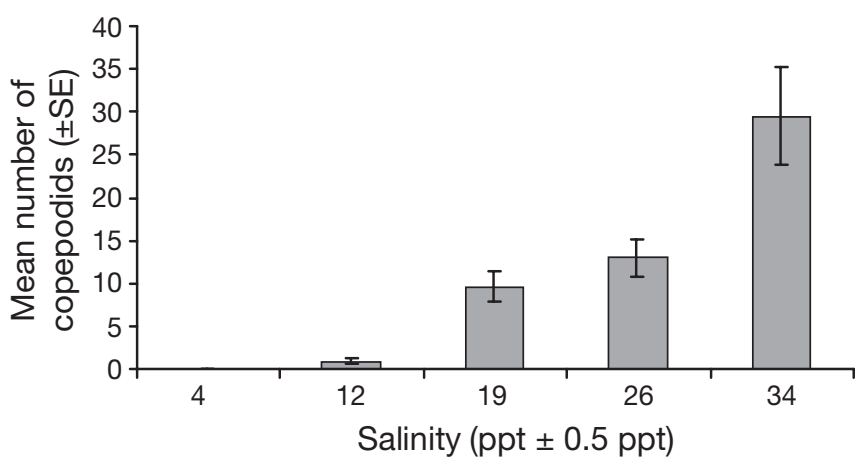

Fig. 4. Lepeophtheirus salmonis. Copepodid infection levels on Salmo salar following $3 \mathrm{~h}$ exposure of copepodids to different salinity levels ( $\mathrm{N}=12$ smolts per salinity level)
$0.5 \mathrm{ppt}$. In Treatment 2, $(12 \pm 0.5 \mathrm{ppt})$, there was a lower infection on $S$. salar and the numbers of chalimus and copepodids found attached to the fish did not differ significantly. At the higher salinity levels (>19 $\pm 0.5 \mathrm{ppt})$, the number of chalimus attached to the fish was significantly lower (Mann-Whitney $U$-test: $\mathrm{p}<0.05$ ) than the number of copepodids at each salinity level (Fig. 5), the number of attached chalimus being approximately $66 \%$ of the number of attached copepodids. This reduction in the number of attached chalimus compared to attached copepodids did not vary significantly between higher salinity levels. At 26 ppt the infection level on $S$. salar smolts was $48 \%$ lower than that at 34 ppt. This is lower than would be predicted from the corresponding survival found for free-swimming copepodids, where a reduction of $<14$ to $16 \%$ would be predicted after 3 to $4 \mathrm{~h}$ exposure to 26 ppt. A similar relationship between survival of free-swimming copepodids and attached copepodids is seen in comparisons between survival and attachment at 26 and 19 ppt. This apparent pattern reversed at $12 \mathrm{ppt}$, where the percentage of surviving copepodids relative to that at 19 ppt was greater for those attached to fish (67\% decrease) than for free-swimming individuals (81 to $87 \%$ decrease).

Salinity level was found not to affect the attachment position of either copepodids or chalimus, although the percentage of individuals attached to different body regions did differ significantly (2-way ANOVA: $F_{9,60}=$ 11.34, $\mathrm{p} \leq 0.001)$. The percentage of individuals attached to different body regions also varied significantly between copepodids and chalimus (2-way ANOVA: $\left.F_{9,60}=2.56, \mathrm{p}=0.015\right): 76 \%$ of chalimus stages were attached to the tail and fins, with only $24 \%$ attached to the body surface. The fin and tail regions also had a high level of attachment for the copepodids (54\%), but a significantly larger percentage (46\%) was found attached to the body surface.

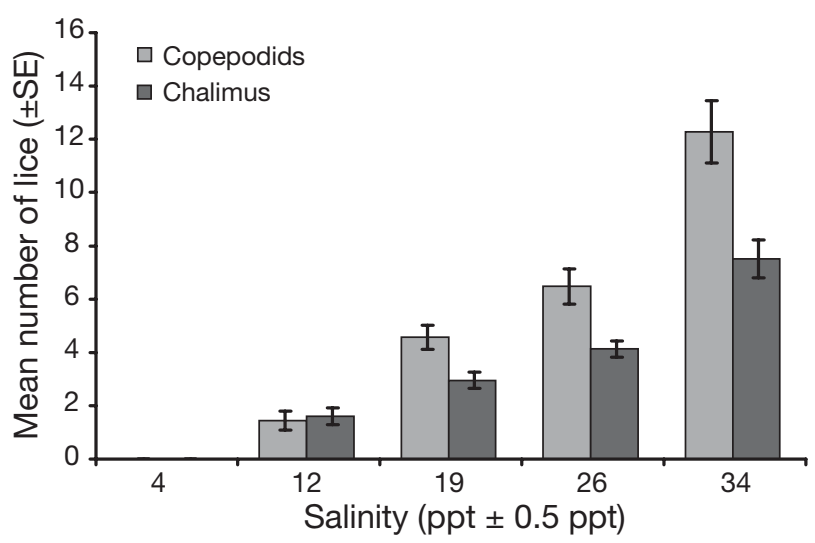

Fig. 5. Lepeophtheirus salmonis. Levels of copepodid $(\mathrm{N}=25$ per salinity) and chalimus infection on Salmo salar smolts ( $\mathrm{N}=$ 26 per salinity) following $3 \mathrm{~h}$ post-infection exposure to different salinity levels 


\section{Attachment to gills}

Copepodids found attached to the gills were not included in the overall analysis of this data. Sevatdal (2001) reported that gill attachment is generally considered to be an artefact of the artificial infection methods used in the laboratory and, anecdotally at least, Lepeophtheirus salmonis chalimus stages are not usually found attached to the gills on wild salmonids.

\section{DISCUSSION}

Lepeophtheirus salmonis is stenohaline (Hahnenkamp \& Fyhn 1985), and is thus unable to osmoregulate effectively outside its physiologically optimum environment. For this reason it was hypothesised that the copepodid stage of $L$. salmonis would only be able to survive in a narrow range of salinities around that of full strength seawater (Jones 1998). At reduced salinity, such as that around a river mouth, survival may be severely compromised. The results of this study demonstrate that short-term exposure to salinity below 29 ppt significantly reduces survival of $L$. salmonis copepodids. Some individuals, however, seem able to survive short periods of exposure to reduced saline conditions and remain infective.

Reduced survival with decreasing salinity is due to copepodids experiencing osmoregulatory problems such as an inability to regulate cell volume or dilution of the haemolymph, resulting in nerve transmission failure. Below 29 ppt their tolerance of a dilute environment decreases with decreasing salinity. Hahnenkamp \& Fyhn (1985) reported free-swimming adult female Lepeophtheirus salmonis to be hyperosmotic down to $12 \mathrm{ppt}$, where they were shown to be capable of surviving for at least $7 \mathrm{~d}$, but did not indicate how reproductively successful they were or if their longterm survival was adversely affected. Below $12 \mathrm{ppt}$ their haemolymph becomes rapidly diluted, they are unable to regulate cell volume, and die within a few hours (Hahnenkamp \& Fyhn 1985). This occurs in copepodids when they can osmoregulate below $29 \mathrm{ppt}$, but are unable to do so below 16 ppt. Hyperosmotic regulation would be energetically costly to $L$. salmonis copepodids, which are lecithotrophic, and thus increased energy demands might significantly reduce survival time (Torres et al. 2002). The rapid increase in $50 \%$ mortality rate to $<60 \mathrm{~min}$ at $12 \mathrm{ppt}$ and lower suggests that below this point the copepodids are unable to regulate cell volume or dilution of the haemolymph. At 15 ppt and $10^{\circ} \mathrm{C}$, Johnson \& Albright (1991a) found that copepodids survived for much shorter periods (approx. 2 d) than free-swimming adult females (approx. $13 \mathrm{~d}$ ). This discrepancy between the survival of the copepodid and adult may be due to the larger surface area to volume ratio of copepodids that would make them more susceptible to ion loss in a dilute environment.

The reduction in survival of copepodids below $29 \mathrm{ppt}$ contradicts the findings of Johnson \& Albright (1991a), which suggested that maximum survival occurred at 25 ppt at $10^{\circ} \mathrm{C}$. However, Johnson \& Albright (1991a) did report that active larval Lepeophteirus salmonis succesfully moulted to the infective copepodid stage at salinities above $30 \mathrm{ppt}$. It is possible that the increasing age of the copepodids used in our experiment resulted in this variation in survival times. The copepodids we used were 2 to $3 \mathrm{~d}$ post-moult when used in the survival experiments. Attachment of the copepodids to a salmonid host does not improve survival at reduced salinity levels. Unlike adult $L$. salmonis, copepodids and chalimus stages cannot use ions obtained from the host to replace those lost to the hypoosmotic environment (Hahnenkamp \& Fyhn 1985). It is also possible that copepodids that attach to a host in low salinity regimes actively detach in an attempt to move to areas where salinity is higher. This is considered to be unlikely, as the chance of encountering another host in natural conditions is considered very low and may be energetically too demanding for the parasite.

In salinities of 19, 26 and $34 \mathrm{ppt}$, chalimus numbers were approximately $66 \%$ of the copepodid numbers found on the fish, representing a significant loss of individuals during moult from copepodid to Chalimus I. This value is comparable with reductions in numbers between copepodid and chalimus infection found elsewhere (Sevatdal 2001). The reduction may be due to copepodids dropping off the fish following initial infection but before they develop to Chalimus I stage, or to a failure to moult to Chalimus I stage. The variation seen here between the position of attachment of copepodids and chalimus suggests that selective survival may be occurring. In this study a higher percentage of chalimus stages than copepodids were attached to the fin regions. After attachment, fins conferred higher survival rates than other attachment sites. However, copepodids may migrate to other regions of the body prior to moulting to the chalimus stage. Lack of variation in the proportion of copepodids successfully developing to chalimus at the 3 higher salinities $(19,26$ and $34 \mathrm{ppt}$ ) clearly demonstrates that there is no long-term impact on development from short-term exposure to decreased salinities. This result agrees with the observations of Tucker et al. (2000b), whereby the onset of senility in copepodids only affects initial infection and no variation is seen in the development rates to Chalimus I. Continued exposure to decreased salinity during development does seem to adversely impact the survival between chalimid stages (Fig. 5). 
In reduced salinity environments Leptophtheirus salmonis copepodids appear to undergo a reduction in their ability to infect Salmo salar smolts under experimental conditions. This is demonstrated by comparisons between the survival of free-swimming copepodids and the numbers able to infect at different salinity levels, whereby the infection was lower than would be predicted from survival experiments. This result agrees with the findings of Tucker et al. (2000a), who demonstrated a lower infection rate at $24 \mathrm{ppt}$ than at 34 ppt.

Lower salinity reduces the activity level of the copepodids, and hence their ability to respond to host cues. A reduction in settlement has been found with increased age in copepodids, coinciding with a decrease in their energy reserves (Tucker et al. 2000b). It is proposed that the physiological stresses associated with a decrease in salinity rapidly deplete the copepodid's energy reserves. If this is the case, exposure to lower salinity regimes may cause premature senility in a copepodid, giving settlement success levels similar to those observed in older individuals.

In previous studies the fins were identified as preferential settlement sites of Lepeophtheirus salmonis (Bron et al. 1991, Tucker et al. 2000a,b). In this study, no significant variation was found in the position of settlement of copepodids on Salmo salar between the different salinity levels. This conflicts with previous findings that at higher salinity levels a greater level of settlement occurs on the body surface (Tucker et al. 2000a). This may, however, be an artefact of the infection methods used in the 2 studies: a bath infection method was used by Tucker et al. (2000a), the dip method of Sevatdal (2001) was used in the current study. Settlement on the body is more energetically demanding on copepodids as they have no protection from drag during the host's swimming behaviour (as suggested by Bron et al. 1991) and this turbulence adversely affects the long term survival of both copepodid and chalimus. With the bath method fish are actively swimming and so attachment may be impacted by water flow across the surface of the fish, whereas in the dip method the fish are stationary during infection so the relative protection provided by the fins will be less important.

Fewer copepodids were attached to the fish in the second sampling time point of the experiment examining the effects of post-infection exposure to salinity, when the fish were significantly larger than in the first block. This conflicts with previous studies by Tucker et al. $(2000 a, b)$, who found larger fish generally had a higher infection level (albeit lower density) than smaller fish. An explanation for this discrepancy is an increase in ambient water temperature between Sampling time points 1 and 2 . This would have resulted in the copepodids in time point 2 being slightly more developed (Johnson \& Albright 1991b, Boxaspen \& Naess 2000), and generally there is a slight decrease in infection level with increasing larval development (Sevatdal 2001). This hypothesis is further supported by a lack of significant variation in the chalimus infection levels between the 2 sampling time points in this study.

The use of haloclines by Leptophtheirus salmonis has been proposed as a host-finding mechanism, as odour from host species may lie in thin layers where a density gradient occurs (Heuch 1995). In this study no evidence was found for copepodids gathering at haloclines, rather their distribution seemed to be a function of their behaviour over a range of salinities. At 35 and 27 ppt, copepodids gathered near the surface whether lit from above or by diffuse ambient light. This agrees with observations that L. salmonis demonstrates reverse diurnal migration, gathering near the surface of the water column during daylight (Heuch et al. 1995). This distribution pattern results in active swimming towards the surface of the water column, followed by passive sinking.

Avoidance behaviour was seen at the lower salinity levels, including a change in the copepodids' orientation to a vertical sinking position, and occasionally active downward swimming. The avoidance of lower salinity levels contradicts findings that diurnal migration is not affected by salinity down to 21 ppt or by temperature in large sea enclosures (Heuch et al. 1995). These results also disagree with a previous study by Heuch (1995) on salinity gradients, where copepodids were found to congregate in salinities of 19 to $24 \mathrm{ppt}$ during the day, and in salinities as low as 15 to $17.2 \mathrm{ppt}$ at night. It seems unlikely that copepodids would remain in these low salinity levels given an option, as below 29 ppt their survival and infective ability is severely compromised (Tucker et al. 2000a). From this point of view the findings of our study conform more closely to what is known of Leptophtheirus salmonis biology, and the behavioural observations are supported by the survival and infection results.

It is feasible that Leptophtheirus salmonis copepodids avoid regions of low salinity because of increased energy expenditure which, in turn, reduces their survival time (Torres et al. 2002). Energy may be expended either for hyperosmotic osmoregulation of cell volume (as in adult females Hahnenkamp \& Fyhn 1985), or for maintenance of their position in the water column, necessiated by their innate negative buoyancy. Sinking rates increased with decreasing salinity, strongly suggesting that copepodids would have to expend more energy to remain in the upper water column. Although distribution in columns of 27 and 35 ppt salinity did not differ significantly, when given a choice more copepodids gathered in the 35 ppt band. 
This indicates that, given a choice, copepodids will remain in full strength seawater. As survival times are significantly decreased below 26 ppt salinity compared to full strength (35 ppt) seawater, this could be an important survival mechanism. Potentially, the reduction in survival arose from increased energy expenditure at 26 ppt or below. The observation that copepodids do not actively avoid 27 ppt either by downward swimming or sinking in the vertical position suggests that this salinity is not directly physiologically damaging to them, as is suggested for the lower salinity levels.

It has been proposed that Lepeophtheirus salmonis copepodids may actively migrate to river mouths to gather in regions where high concentrations of salmonid smolts will be present, and hence improve their probability of successfully infecting a host (Carr \& Whoriskey 2004, Costello et al. 2004, McKibben \& Hay 2004). Copepodids are capable of actively altering their position in the water column in response to a number of environmental variables including light, salinity and pressure (Bron et al. 1993, Heuch 1995). Combining their responses with these variables could allow copepodids to utilise tidal transport to move inshore and possibly towards the base of a river. Other larval crustaceans are known to utilise tidal transport to travel into inshore areas (Xiao \& Greenwood 1992, Tankersley et al. 1998, El-Darsh \& Whitfield 1999, McKibben \& Hay 2004). All these studies, however, deal with decapods, the life histories of which differ from that of $L$. salmonis.

Sea lice have been shown to respond both directionally and with increased activity to odour from Salmo salar (Ingvarsdottir et al. 2002). Positioning close to a halocline may also increase their host encounter rate (Lyse et al. 1998, Finstad et al. 2000). The behaviour of copepodids, whereby they will continue to swim upwards until a region of low salinity is encountered, would maintain their position in the water column just below a halocline. Whether this occurs under natural conditions is currently unknown. It would be difficult to ascertain whether this is an adaptive behaviour for an inshore dwelling species, or an artefact of responses to environmental variables of a primarily oceanic species. Distribution just beneath a halocline may well occur if the copepodid's behaviour of reverse diurnal migration (Heuch et al. 1995) is coupled with a sinking response to reduced salinity, as found in this study.

Available data on the distribution of copepodids in estuarine areas in Ireland suggests that for the majority of the year copepodids are not found near the mouths of rivers (Costello et al. 1998b), but that high concentrations coincide with the seaward migration of smolts and the freshwater migration of adult Salmo salar (Costello et al. 1998b, McKibben \& Hay 2004). S. salar frequently congregate near to the mouths of rivers prior to their upstream migration, particularly at times when water flow from the river is low, and it is possible that the occurrence of copepodids near the mouths of rivers arises from the hatching of egg strings originating from adults on the upward migrating fish (Jonsson et al. 1990, Smith et al. 1994). The relatively rapid migration of salmonids into river systems during periods of high water flow may also account for the lack of copepodids found around river mouths during periods of high rainfall (Costello et al. 1998a,b).

Studies of local currents in estuarine areas suggest that larval transport is only possible over long distances if the larvae rest on the sediment during an ebb tide and are only in the water column during the flood tide (Costello et al. 1998a,b, Kimmerer et al. 1998). This pattern of behaviour was not observed in this study, suggesting that the copepodids remain distributed in the water column as previously proposed by Heuch et al. (1995).

The results of this study show that if copepodids actively gather around river mouths they may not increase their infection rate on potential hosts. If they move into a dilute halocline where the majority of fish are likely to be, they will compromise both their survival and infection abilities if they infect Salmo trutta. This species tends to remain in regions of low salinity immediately following seawater transfer to meet its own osmoregulatory requirements (Lyse et al. 1998), and any attached copepodids would be exposed to suboptimal salinity conditions.

If Lepeophtheirus salmonis copepodids reside immediately below the halocline they have the potential to infect any salmonids moving through the halocline. Their behavioural response to reduced salinity suggests that copepodids will respond to reduced salinity in surface waters by positioning themselves lower in the water column. This will increase their survival around regions of reduced salinity. However, in the shallow water around the mouths of rivers, haloclines will only be present on an intermittent basis, if at all. The shallow depth of the water will result in mixing of the water column, forming a uniform low salinity environment. This would be particularly relevant at times of heavy rainfall and high wind when salinity levels around river mouths declines. This has been observed under wild conditions when a lack of free-swimming copepodids was observed around river mouths following heavy rainfall (Costello et al. 1998a,b).

In conclusion, the findings of this study show that infection of seaward migrating salmonid smolts with Lepeophtheirus salmonis copepodids does not occur in estuaries or at the mouths of rivers where the environment is not conducive to long term copepodid survival or optimum settlement conditions. It is proposed that $L$. salmonis settlement on newly migrated smolts occurs 
in the coastal zone away from river mouths and at salinities that are closer to oceanic seawater and higher than 27 ppt.

\section{LITERATURE CITED}

Berland BI (1993) Salmon lice on wild salmon (Salmo salar L.) in western Norway. In: Boxshall GA, Defaye D (eds) Pathogens of wild and farmed fish: sea lice. Ellis Horwood, Chichester, p 179-187

Bjørn PA, Finstad B, Kristoffersen R (2001) Salmon lice infection of wild sea trout and Arctic char in marine and freshwaters: the effects of salmon farms. Aquac Res 32:947-962

Boxaspen K, Naess T (2000) Development of eggs and the planktonic stages of salmon lice (Lepeophtheirus salmonis) at low temperatures. Contrib Zool 69:51-55

Bron JE, Sommerville C, Jones M, Rae GH (1991) The settlement and attachment of early stages of the salmon louse, Lepeophtheirus salmonis (Copepoda, Caligidae) on the salmon host, Salmo salar. J Zool 224:201-212

Bron JE, Sommerville C, Rae GH (1993) Aspects of the behaviour of copepodid larvae of the salmon louse, (Lepeophtheirus salmonis) (Krøyer, 1837). In: Boxshall GA, Defaye DD (eds) Pathogens of wild and farmed fish: sea lice. Ellis Horwood, New York, p 125-142

Butler JRA (2002) Wild salmonids and sea louse infestations on the west coast of Scotland: sources of infection and implications for the management of marine salmon farms. Pest Manag Sci 58:595-608

Carr J, Whoriskey F (2004) Sea lice infestation rates on wild and escaped farmed Atlantic salmon (Salmo salar L.) entering the Magaguadavic River, New Brunswick. Aquac Res 35:723-729

Costello M, Costello J, Roche N (1996) Planktonic dispersion of larval salmon lice, Lepeophtheirus salmonis, associated with cultured salmon, Salmo salar, in Western Ireland. J Mar Biol Assoc, UK 76:141-149

Costello M, Costello J, Coghlan N, O'Donohoe G, O'Connor B (1998a) Distribution of the larval stages of Lepeophtheirus salmonis in three bays on the west coast of Ireland. ICES J Mar Sci 55:181-187

Costello M, Costello J, O'Donohoe G, Coghlan NJ, Oonk M, van der Heijden Y (1998b) Planktonic distribution of sea lice larvae, Lepeophtheirus salmonis, in Killary Harbour, west coast of Ireland. J Mar Biol Assoc UK 78:853-874

Costello MJ (1993) Review of methods to control sea lice (Caligidae: Crustacea) infestations on salmon (Salmo salar) farms. In: Boxshall GA, Defaye D (eds) Pathogens of wild and farmed fish: sea lice. Ellis Horwood, Chichester, p 219-252

Costello MJ, Burridge L, Chang B, Robichaud L (2004) Sea lice (2003) Proceedings of the sixth international conference on sea lice biology and control. Aquac Res 35: 711-712

El-Darsh HEM, Whitfield PJ (1999) The parasite community infecting flounders, Platichthys flesus, in the tidal Thames. J Helminthol 73:203-214

Finstad B, Bjørn PA, Grimmes A, Hvidsten NA (2000) Laboratory and field investigations of salmon lice [Lepeophtheirus salmonis (Krøyer)] infestation on Atlantic salmon (Salmo salar L.) post-smolts. Aquac Res 31:795-803

Hahnenkamp L, Fyhn HJ (1985) The osmotic response of salmon louse, Lepeophtheirus salmonis (Copepoda, Caligidae), during the transition from seawater to freshwater. J Comp Physiol B 155:357-365
Heuch PA (1995) Experimental evidence for aggregation of salmon louse copepodids (Lepeophtheirus salmonis) in step-salinity gradients. J Mar Biol Assoc UK 75:927-939

Heuch PA, Parsons A, Boxaspen K (1995) Diurnal vertical migration: a possible host-finding mechanism in salmon louse (Lepeophtheirus salmonis) copepodids? Can J Fish Aquat Sci 52:681-689

Ingvarsdottir A, Birkett MA, Duce I, Genna RL, Mordue W, Pickett JA, Wadhams LJ, Mordue AJ (2002) Semiochemical strategies for sea louse control: host location cues. Pest Manag Sci 58:537-545

Jacobsen JA, Gaard E (1997) Open-ocean infestation by salmon lice (Lepeophtheirus salmonis): comparison of wild and escaped farmed Atlantic salmon (Salmo salar L.). ICES J Mar Sci 54:1113-1119

Johnson SC, Albright LJ (1991a) Development, growth, and survival of Lepeophtheirus salmonis (Copepoda, Caligidae) under laboratory conditions. J Mar Biol Assoc UK 71: 425-436

Johnson SC Albright LJ (1991b) The developmental stages of Lepeophtheirus salmonis (Krøyer, 1837) (Copepoda, Caligidae). Can J Zool 69:929-950

Jones JB (1998) Distant water sailors: parasitic Copepoda of the open ocean. J Mar Syst 15:207-214

Jonsson N, Jonsson B, Hansen LP (1990) Partial segregation in the timing of migration of Atlantic salmon of different ages. Anim Behav 40:313-321

Kimmerer WJ, Burau JR Bennett WA (1998) Tidally oriented vertical migration and position maintenance of zooplankton in a temperate estuary. Limnol Oceanogr 43:1697-1709

Lyse AA, Stefansson SO, Fernö A (1998) Behaviour and diet of sea trout post-smolts in a Norwegian fjord system. J Fish Biol 923-936

MacKenzie K, Longshaw M, Begg GS McVicar AH (1998) Sea lice (Copepoda: Caligidae) on wild sea trout (Salmo trutta L.) in Scotland. ICES J Mar Sci 55:151-162

McKibben MA, Hay DW (2004) Distributions of planktonic sea lice larvae Lepeophtheirus salmonis in the inter-tidal zone in Loch Torridon, Western Scotland in relation to salmon farm production cycles. Aquac Res 35:742-750

Moore A, Ives M, Scott M, Bamber S (1998a) The migratory behaviour of wild sea trout (Salmo trutta L.) smolts in the estuary of the River Conwy, North Wales. Aquaculture 168:57-68

Moore A, Ives S, Mead TA, Talks L (1998b) The migratory behaviour of wild Atlantic salmon (Salmo salar L.) smolts in the River Test and Southampton Water, southern England. Hydrobiologia 372:295-304

Parrish DL, Behnke RJ, Gephard SR, McCormick SD, Reeves GH (1998) Why aren't there more Atlantic salmon (Salmo salar)? Can J Fish Aquat Sci 55:281-287

Pike AW, Wadsworth SL (2000) Sea lice on salmonids: their biology and control. Adv Parasitol 44:233-337

Schram TA (1993) Supplementary descriptions of the developmental stages of Lepeophtheirus salmonis (Krøyer, 1837) (Copepoda: Caligidae). In: Boxshall GA, Defaye DD (eds) Pathogens of wild and farmed fish: sea lice. Ellis Horwood, New York, p 30-50

Scott D (2001) Chemical pollution as a factor affecting the sea survival of Atlantic salmon, Salmo salar L. Fish Manag Ecol 8:487-499

Sevatdal S (2001) An improved method for experimental infection of salmon (Salmo salar L.) with salmon lice, Lepeophtheirus salmonis (Kroyer). Bull Euro Assoc Fish Pathol 21:109-113

Smith GW, Smith IP, Armstrong SM (1994) The relationship between river flow and entry to the Aberdeenshire Dee by 
returning adult Atlantic salmon. J Fish Biol 48:925-936

Tankersley RA, Wieber MG, Sigala MA, Kachurak KA (1998) Migratory behavior of ovigerous blue crabs Callinectes sapidus: evidence for selective tidal-stream transport. Biol Bull (Woods Hole) 195:147-153

Torres G, Gimenez L, Anger K (2002) Effects of reduced salinity on the biochemical composition (lipid, protein) of zoea I decapod crustacean larvae. J Exp Mar Biol Ecol 277: $43-60$

Tucker CS, Sommerville C, Wootten R (2000a) The effect of temperature and salinity on the settlement and survival of copepodids of Lepeophtheirus salmonis (Krøyer, 1837) on Atlantic salmon, Salmo salar L. J Fish Dis 23:309-320

Tucker CS, Sommerville C, Wootten R (2000b) An investigation into the larval energetics and settlement of the sea

Editorial responsibility: Dieter Steinhagen,

Hannover, Germany louse, Lepeophtheirus salmonis, an ectoparasitic copepod of Atlantic salmon, Salmo salar. Fish Pathol 35:137-143

Tully O, Nolan DT (2002) A review of the population biology and host-parasite interactions of the sea louse Lepeophtheirus salmonis (Copepoda: Caligidae). Parasitol 124: S165-S182

Tully O, Gargan P, Poole WR, Whelan KF (1999) Spatial and temporal variation in the infestation of sea trout (Salmo trutta L.) by the caligid copepod Lepeophtheirus salmonis (Kroyer) in relation to sources of infection in Ireland. Parasitol 119:41-51

Xiao Y, Greenwood JG (1992) Distribution and behavior of Acetes sibogae Hansen (Decapoda, Crustacea) in an estuary in relation to tidal and diel environmental changes. J Plankton Res 14:393-407

Submitted: November 11, 2005; Accepted: March 27, 2006 Proofs received from author(s): August 21, 2006 